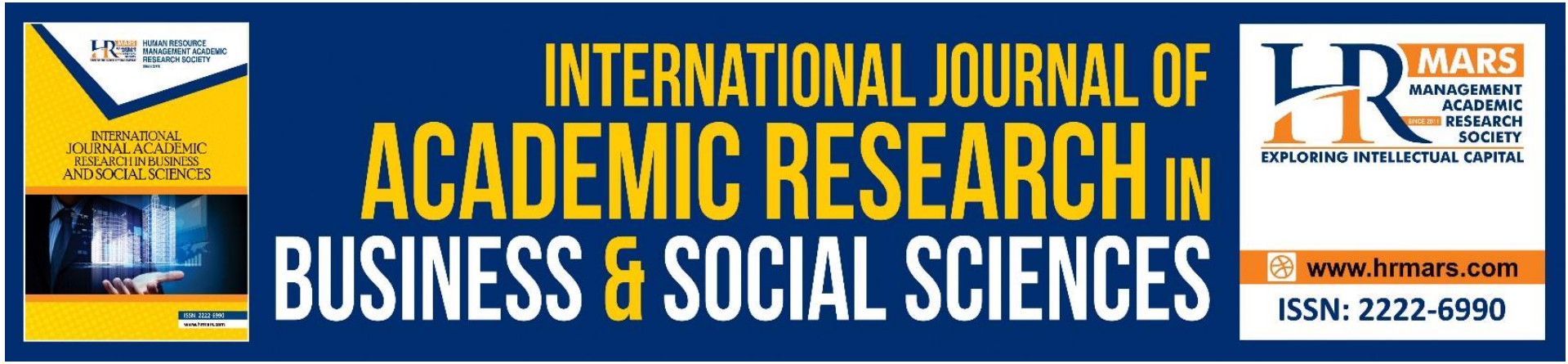

\title{
The Impact of Supervisor-Nurse Relationships, Cooperative Communication and Team Effectiveness: A Study of Nursing Team
}

Farah Lina Azizan, Muhammad Aiman Arifin, Athifah Najwani Shahidan, Noraini Othman

To Link this Article: http://dx.doi.org/10.6007/IJARBSS/v11-i8/10168 DOI:10.6007/IJARBSS/v11-i8/10168

Received: 11 June 2021, Revised: 15 July 2021, Accepted: 31 July 2021

Published Online: 13 August 2021

In-Text Citation: (Azizan et al., 2021)

To Cite this Article: Azizan, F. L., Arifin, M. A., Shahidan, A. N., \& Othman, N. (2021). The Impact of SupervisorNurse Relationships, Cooperative Communication and Team Effectiveness: A Study of Nursing Team. International Journal of Academic Research in Business and Social Sciences, 11(8), 550-564.

Copyright: @ 2021 The Author(s)

Published by Human Resource Management Academic Research Society (www.hrmars.com) This article is published under the Creative Commons Attribution (CC BY 4.0) license. Anyone may reproduce, distribute, translate and create derivative works of this article (for both commercial and non-commercial purposes), subject to full attribution to the original publication and authors. The full terms of this license may be seen at: http://creativecommons.org/licences/by/4.0/legalcode

Vol. 11, No. 8, 2021, Pg. 550 - 564

Full Terms \& Conditions of access and use can be found at http://hrmars.com/index.php/pages/detail/publication-ethics 


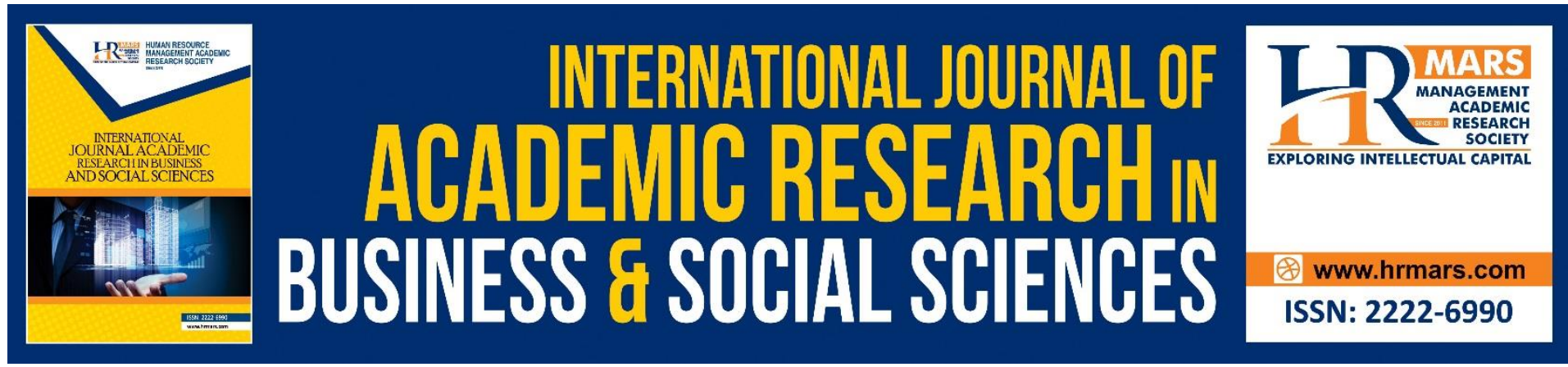

\title{
The Impact of Supervisor-Nurse Relationships, Cooperative Communication and Team Effectiveness: A Study of Nursing Team
}

\author{
aFarah Lina Azizan, bMuhammad Aiman Arifin, ' ${ }^{\mathrm{a}}$ Athifah Najwani \\ Shahidan, dNoraini Othman \\ a,b,c Faculty of Business and Management, Universiti Teknologi Mara Cawangan Perlis, \\ Kampus Arau, 02600 Arau, Perlis, Malaysia, 'School of Business Management, Universiti \\ Utara Malaysia \\ Email: farahlina@uitm.edu.my, aimanarifin@uitm.edu.my, athifahnajwani@uitm.edu.my, \\ n.aini@uum.edu.my
}

\begin{abstract}
In the healthcare industry, teamwork is a critical element in ensuring patients' safety and quality of care. A higher level of organisational performance can be achieved by teamwork compared to individual work due to the combination of team members' knowledge, skills, experience, and energy. This research aims to uncover the connection between nursesupervisor relationship and cooperative communication with team effectiveness. This work also examines how cooperative communication mediates supervisor-nurse relationship and team effectiveness. The research employed a quantitative approach involving 475 staff nurses representing 95 wards in general hospitals in Malaysia. The findings reveal supervisor-nurse relationship and cooperative communication are positively related to team effectiveness. Further, cooperative communication is found to have a mediating effect on supervisor-nurse relationship and team effectiveness. This study suggests that a leader should assist team members towards an effective teamwork environment. This study also contributes to new literature in team and leadership theories.
\end{abstract}

Keywords: Team Effectiveness, Supervisor-Nurse Relationship, Cooperative Communication, Nursing Team

\section{Introduction}

In healthcare organisations, nurses act as a focal component to represent the organisations' capability since they need to interact with patients directly. As the patients' health outcomes are dependent on effective teamwork among nurses, there is a need for a better preparation of nurses in teamwork (Sonoda et al., 2018). Under these circumstances, nurses should regularly work together because teamwork represents a vital facet of healthcare provision. As indicated by Hughes et al (2016), successful teamwork is very closely related to patient safety, saving lives, and fewer medical errors. Hence, it can be asserted that effective team functioning is one of the main causes of healthcare organisational achievement. 
Furthermore, Polis et al (2017) argued that teamwork is hugely important in the profession of nursing to ensure that patient safety is achieved and thus increase the satisfaction of the patient as well as the staff themselves. Patients in a hospital comprise the elderly, severely ill, and chronically ill. Therefore, the work environment should also be in a good condition as the nurses' workload is very heavy (Nelsey \& Brownie, 2012; Polis et al., 2017), which consequently affect the health team's spirit of teamwork. Medical errors affecting patients' safety can also occur if there is a lack of effective teamwork (Kalisch et al., 2010; Welp et al., 2016). Accordingly, healthcare management should take seriously the issue of teamwork effectiveness among nurses.

In the context of health care involving older patients and the rise in chronic diseases, the use of human resources is very critical for nurses as they face big challenges. The nursing profession is still facing the problem of shortage of staff and high turnover rates (Anderson, 2019; Kalisch \& Lee, 2010). In Malaysia, currently about 70\% of hospitals do not have enough nursing staff and many skilled and experienced nurses have shifted from the public sector to the private sector or moved overseas (Ong et al., 2018). Kalisch and Lee (2010) indicated that having a sufficient workforce is needed for nurses to be able work together as a team. They also stressed that teamwork efficiency will increase if there is a large number of workers.

Particularly, previous research stated that a high-quality supervisor-nurse relationship has been identified as one of the key factors influencing team outcome (Adams et al., 2019; Brunetto et al., 2011). Kaiser and Wester (2018) also stressed that the higher the quality of relationships between supervisors and subordinates, the higher the effectiveness of teamwork and subsequently the goals of an organisation will be achieved. Yet, there are still few studies examining the relationship of nurse-supervisors to teamwork performance among nurses (Brunetto et al., 2016). As the performance level assessment is conducted by the supervisor, supervisors will then have to use their management power in order to improve the quality of work among their subordinates (Havold \& Havold, 2019).

Furthermore, previous studies suggested that factors such leadership and communication are very important in influencing nursing team outcomes (Grover et al., 2017; Mitchell et al., 2015). The aspects of leadership, communication, and teamwork are closely related. Leadership is a base element to provide a good framework and a communication system is needed to achieve organisational development (Ferlie \& Shortell, 2001). Cooperative communication between staff nurses supports information sharing that impacts care delivery (Gharaveis et al., 2018). A relationship in a good environment where the employer supports employee cohesion and good communication between employees can build an effective team and in turn can also improve organisational performance (Ulrich, 2017).

During the researchers' interview with the Head Matron, there were several issues addressed that concerned teamwork among Malaysian nurses. Among the issues that arose were the frequency of nurses' absences, low morale symptoms, and dissatisfaction among nurses in the nursing unit. Furthermore, the nurses complained about the weak communication and responses in handling conflicts in the nursing units. A decreased team spirit among nurses can have a detrimental effect on the condition of patients and have an impact on nurses' profession. They show a negative and bad attitude and fail to cooperate with each other in carrying out tasks which results in insufficient patient care procedures at the end of the shift, 
and in turn will result in dissatisfaction among nurses in the unit. Therefore, it can be argued that when the team is established effectively through good communication and relationships between supervisor and nurses, the organisational problems can be solved more proficiently and as a consequence, high organisational performance will be achieved.

In this study, the researchers examined the impact of nurse-supervisor relationship and cooperative communication on team effectiveness. The present study also investigated cooperative communication as a mediating effect on the relationship between supervisornurse relationship and team effectiveness. Thus far, the role of cooperative communication as a mediator of the influence of supervisor-nurse relationship on team effectiveness has not been addressed adequately, particularly in the non-western literature and healthcare industry. Therefore, this study would present an in-depth knowledge of the potential role of cooperative communication in the relationship between supervisor-nurse relationship and team effectiveness.

\section{Review of Literature LMX Theory}

Leader-member exchange (LMX) theory refers to the concept of leadership in which a leader develops a unique one-to-one relationship with employees, treating the employees differently and achieving different outcomes; these result in the in-group and out-group. The 'in-group' receives high degrees of mutual support, respect, and trust as well as enhanced access to knowledge and involvement in the process of making decisions (Mueller \& Lee, 2002). Accordingly, employees who are in this group (in-group) will get benefits such as promotions, bonuses, and even greater control over the workload (Wassem et al., 2019), and in return, employees who feel that the supervisor supports them will always show support towards their supervisor (Huang et al., 2021). Therefore, in the context of healthcare delivery, the patient's outcome is positive as 'in-group' employees find it easier to carry out the job and resolve work-related problems. In terms of the 'out-group', it involves a limited exchange relationship between leader and employee. In other words, an out-group member will carry out routine tasks according to the contract given and without carrying out the tasks that are not in the structure. In healthcare, nurses who are in the 'out-group' start to feel forgotten, left behind, and abused. They may feel that their position is fixed, leaving them with no purpose to change their professional behaviour (James et al., 2021).

Thus, using this underpinning theory of LMX, it is anticipated that a high quality relationship between leader and employee will influence the cooperative communication among team members and in turn, influences the effectiveness of team outcome, because it influences the exchange of information, sources, encouragement, and the level of participation in decisionmaking. Consequently, this is expected to influence the nurses' expectations of wellbeing. In contrast, a low-quality relationship between leader and employee involves diverse messages from the leader along with weak information flow and resources among team members. Such factors are ideal to establish weak perceptions of teamwork which leads to higher confusion as nurses serve their patients. Still, the connections between these variables are still being studied, and so this area needs to be investigated. 


\section{Supervisor-nurse Relationship}

Previous research indicated that the supervisor is responsible for maintaining close relationships with only a few subordinates due to time-pressure and lack of resources (Cogliser \& Schriesheim, 2000; Sui et al., 2016). However, this strategy is not aimed at attempting to control nurses directly via their supervisors especially in public sector professions; instead, it aims to transfer nurse supervisors into managers, as such assigning the duty for accomplishing organisational goals (usually objectives of raising efficiency by 'doing more with less') to them (Othman \& Nasurdin, 2019). The supervisors are then supposed to wield their power to ensure that the nurses under their charge attain organisational goals (Morsiani, Bagnasco, \& Sasso, 2017).

Public sector nurses in Malaysia have undergone standardisation in resource-based service delivery, resulting in intensification of the work (Ahmad \& Saad, 2020). Nurses in the public sector face higher workloads, worse working conditions, rigid work schedules, increased work duration, decreasing autonomy at work, and more responsibilities (Azizan et al., 2017). To a certain degree, supervisors have been forced to use their authority as managers and raise nurses' level of accountability due to the performance indicators endorsed by top management (Brunetto et al., 2011; Srulovici \& Drach-Zahavy, 2017).

\section{Team Effectiveness}

Teams are defined as groups of workers who are dependent on each other; they usually have skills that complement their team members' and pursue common objectives while possessing the potential for achieving excellent performance (Katzenbach \& Smith, 1993). In this study, the effectiveness of a team is characterised as both team satisfaction and team viability. Team satisfaction refers to satisfying the personal needs of team members and team viability is the retention of its members and their readiness to maintain their status as a team (Balkundi \& Harrison, 2006).

Specific group processes that increase trust to enable easy information exchange and support between team members are key to the team's ability for reaching high performance. Supervisors are responsible for being role models to facilitate information sharing and support giving behaviour (Afasar \& Masood, 2018). The establishment of an effective relationship between nurses and supervisors under good management practices and processes will build a trusting and harmonious relationship at work (Rodwell et al., 2017).

A study by Halim and Azizan (2017) have suggested that supervisors who solicit their subordinates' suggestions, are interested in them as people, can casually relate to them, and encourage employees to give ideas when making decisions have a better likelihood of increasing the commitment of subordinates to their work group. A relationship between superior and subordinate that is robust and in harmony will amplify the effectiveness of the team, which in turn will pave the way to reach the goals of the team and general success (Chiniara \& Bentein, 2018; Jha, 2017).

\section{Cooperative Communication}

Cooperative communication is defined by workgroup members' message exchanging behaviours as well as activities which are meant to ease members towards achieving the goals of the workgroup together (Lee, 1997). Cooperative communication behaviours of members 
are the exchange of information, ideas and resources that are shared willingly, providing encouragement, showing concern towards each other, being interested in the activities of fellow group members, responding to group members, showing support and sensitivity that are reciprocal, and engaging in concessions and negotiations to reach agreement towards the goals of the group (Chen et al., 2006).

In the healthcare setting, members of the healthcare team must achieve effective communication to ensure patient care that is safe and highly reliable (Wang et al., 2018). Communication between healthcare team members especially staff nurses must be improved as it is a highly vital due to social and medical conditions that are quickly evolving. Staff nurses who have good communication with each other in a team such as giving adequate information regarding their nursing task on how to handle patient care, will improve their performance and increase satisfaction and intention to stay in the same team. Therefore, the researchers anticipated that cooperative communication significantly influences team effectiveness.

In the nursing profession, good leadership is becoming increasingly vital to teamwork quality because patient outcomes are highly dependent on it (Azizan et al., 2017; Keogh et al., 2019). Communication quality between workers in healthcare is among the crucial factors that affect the outcomes of patients; when there is poor information transfer, there is a significantly higher possibility of adverse outcomes. When there is a lack of cooperative communication among nurses, nurses will experience ambiguity in contact with patients as they do not have clear information or resources (Brunetto et al., 2011; Busari et al., 2017). When there is bad communication in terms of these expectations, relationships, and responsibilities, it will affect the job of the nurse as their work is situated between the patient under care and other professionals in allied health (Borrot et al., 2017).

In practice, this means that when nurses have a high quality of relationship with their supervisor, they will be more likely to get access to pertinent information and resources and in turn will influence cooperative communication between team members, which in turn produces team effectiveness. Therefore, based on the above arguments, the following hypotheses are proposed:

H1: Supervisor-nurse relationship is significantly related to team effectiveness

H2: Cooperative communication is significantly related to team effectiveness

H3: Supervisor-nurse relationship is significantly related to cooperative communication

H4: Cooperative communication is a mediator between supervisor-nurse relationship and team effectiveness

\section{Methodology}

Methodology from the study are discussed from three sections: (1) Study design and participants; (2) Measure and (3) Data aggregation to team level.

\section{Study Design and Participants}

Data collection involved staff nurses (member) and sisters (leader) in public hospitals in Peninsular Malaysia who worked in various specialties such as paediatric, surgery, cardiology, neurology, and emergency medicine. This study used the sampling technique of simple random sampling because it is the simplest and quickest means of selecting a sample (Keyton, 
2014). The pair questionnaires were distributed to nurse who had worked in a team with the minimum time period of 6 months and above in order to develop a mature workplace. This was to ensure that both supervisor and staff nurse had familiarised themselves with each other and developed an exchange relationship (Graen \& Uhl-Bien 1995).

This research was registered with the National Medical Research Registry (NMRR). After obtaining these approvals, the researchers proceeded to deliver the questionnaires to selected public hospitals in Peninsular Malaysia. The questionnaire sheets were given out to the selected 475 staff nurses and 95 sisters, in 95 hospital wards. All of the questionnaires were encoded with identification numbers assigned by the researchers to match staff nurses and sisters. Confidentiality was assured by asking the respondents to seal the questionnaires in the return envelopes after completing them and returning them to the researchers directly.

The researchers received a total of 413 questionnaires from the staff nurses and 86 from the sisters, which resulted in an $87 \%$ response rate. Each team had from three to five respondents (staff nurses) with an average of four respondents which were reported under one supervisor (sisters). The data were entered into an SPSS file and during data entry, the first method used to identify sample bias was eye screening. The data were compared using mean values and our variance analysis yielded no significantly different means for the two groups.

\section{Measure}

In data collection, the first scale used was Team Effectiveness which included two dimensions; team satisfaction and team viability created by Hackman (1990) and Balkundi and Harisson (2006). This scale is composed of 14 items that were rated by a five-point Likert scale which ranged from Strongly disagree to Strongly agree. This instrument obtained a reliability for team satisfaction $(\alpha=0.80)$ and team viability $(\alpha=0.88)$ which were acceptable.

In addition, supervisor-nurse relationship was measured using the LMX scale (leader-member exchange) developed by Liden and Maslyn (1998). This instrument is composed of 12 worded items, which were rated using a Likert scale with a five options range ( 1 = Strongly disagree to $5=$ Strongly agree). Internal consistency was $\alpha=0.94$ for LMX member and $\alpha=0.90$ for LMX leader. This instrument was paired between staff nurse (member) and sister (leader) to form a dyad.

Cooperative Communication was validated by Lee (1997) with seven items, which were rated using a Likert scale with a five options response. This scale's reliability was $\alpha=0.80$.

To test the hypotheses, two variables were controlled to reduce bias (Spector \& Brannick, 2011). Initially, the researchers controlled group size and team tenure as these variables are potentially related to team effectiveness (Liden et al., 2006; Sin et al., 2009). Team tenure was then measured as the logged average number of years that team members had been members of the team and the logarithm of the number of team members was used to measure team size.

\section{Data Aggregation to Team-level}

As the constructs were operationalised as team level, the data were aggregated individual responses on the scale to calculate each team's single score. Within-group interrater reliability $r_{w g}$ (James et al., 1993) and intraclass correlation coefficients (ICC (1) and ICC (2) 
from Bliese (2000) were used to determine the aggregation's appropriateness. The results demonstrated that all mean indices $r_{w g}$, ICC (1), and ICC (2) for team effectiveness $\left(r_{w g}=0.92\right.$, ICC $(1)=0.35, \operatorname{ICC}(2)=0.90, F(91,552)=9.98, p<0.01)$, supervisor-nurse relationship ( $r_{w g}$ $=0.96, \operatorname{ICC}(1)=0.51, \operatorname{ICC}(2)=0.82, F(91,1012)=13.59, \mathrm{p}<0.01)$, and cooperative communication $\left(r_{w g}=0.97, \operatorname{ICC}(1)=0.13, \operatorname{ICC}(2)=0.74, F(91,552)=3.56, p<0.01\right)$ showed acceptable agreements because $r_{w g}$ was higher than 0.70 and ICC (1) was greater than 0.12 . Hence, the aggregation of individual ratings to form team scores was supported by these indicators.

\section{Results}

Findings from the study are discussed in two sections: (1) respondent's demographic information, and (2) hypotheses analysis.

\section{Profile of Respondents}

The sample consisted of 413 staff nurses who were generally female (95.4\%), which is illustrative of the recent nursing workforce in Malaysia. With respect to the nursing education level, $42.5 \%$ held post-basic training, whereas $57.5 \%$ held basic training. Furthermore, the results revealed that these respondents came from various departments such as Anaesthesiology, Cardiology, Day Care, Dermatology, Emergency and Trauma, Ear, Nose, and Throat, General Medical, Nephrology, Neurology, Obstetrics and Gynaecology, Ophthalmology, Orthopaedic, Operation Theatre, Paediatric, Psychiatric, Respiratory, and Surgery. The largest percentage (19.2\%) were from Obstetrics and Gynaecology and the lowest percentage (0.6\%) were from Dermatology. The average age of team members was 37.93 year $(S D=4.24)$, and the team members had been working in their current hospital for an average of 7.05 years $(S D=3.92)$. The results also revealed that the team members had been working in the same team for an average of 4.51 years (SD = 3.76), and team members had been under the supervision of their current supervisor for 3.26 years on average (SD = $2.87)$. Finally, on average the team size was 4.66 people $(S D=0.57)$.

\section{Hypotheses Analysis}

As mentioned earlier, this study proposed that: (1) supervisor-nurse relationship has a significant influence on cooperative communication; (2) supervisor-nurse relationship and cooperative communication have a significant influence on team effectiveness; and (3) cooperative communication has a mediating role between supervisor-nurse relationship and team effectiveness.

$\mathrm{H} 1$ and $\mathrm{H} 2$ were tested by using a hierarchical regression technique. To perform the analysis, the researchers controlled the demographic variables of team size and team tenure. Based on Table 2, for Model 1, the results show that the control variables made up $10.4 \%$ of the variance in cooperative communication $\left(R^{2}=0.104, F\right.$-change $\left.=4.935, p<0.01\right)$. Team size and team tenure were significantly related to cooperative communication $(\beta=-0.202, p<$ $0.01 ; \beta=0.236, p<0.01$ ). When adding supervisor-nurse relationship based on Model 2 , the $R^{2}$ rose to 0.202 . This showed that supervisor-nurse relationship could explain an extra $9.8 \%$ $\left(R^{2}\right.$ - change $\left.=0.098, p<0.01\right)$ of the variance observed in cooperative communication. Supervisor-nurse relationship was significantly related to cooperative communication $(\beta=$ $0.148, \mathrm{p}<0.01)$, thus $\mathrm{H} 1$ was accepted. 
Looking at Model 3 in Table 1, the control variables (team size and team tenure) accounted for $3.9 \%\left(R^{2}=0.039, p<0.05\right)$. The findings showed that team size and team tenure were related to team effectiveness $(\beta=0.104, p<0.05 ; \beta=-0.186, p<0.05)$. This indicated that these two control variables were influencing team effectiveness. Nevertheless, in Model 4, by adding supervisor-nurse relationship and cooperative communication, the $\mathrm{R}^{2}$ increased to 0.088. The findings indicated that all the variables could explain an additional $4.9 \%$ of the variance related to team effectiveness $\left(R^{2}\right.$ - change $\left.=0.049, p<0.01\right)$. Supervisor-nurse relationship and cooperative communication were positively influencing team effectiveness $(\beta=0.237, p<0.01 ; \beta=0.441, p<0.01)$, which meant that $\mathrm{H} 2$ was accepted.

Then, to test the mediating variable (H3), PROCESS macro in SPSS was used (Hayes, 2013). Zhao et al. (2010) suggested using the indirect effect approach to test mediation. PROCESS macro is preferred to the Sobel test because PROCESS macro estimates indirect effects by using bootstrapping, which alleviates the non-normality violation problem of the indirect effect (Preacher et al., 2007).

As shown in Table 2, the indirect effect of supervisor-nurse relationship on team effectiveness via cooperative communication was $0.162(\mathrm{SE}=0.031)$, confidence interval $(\mathrm{Cl})$ for the indirect effect excluded zero (95\% bootstrap $\mathrm{Cl}[0.105,0.229], \mathrm{p}<0.05)$, thus supporting a statistically significant indirect effect. Supervisor-nurse relationship's direct effect on team effectiveness was positively significant $(b=0.781, p<0.01)$. Given that indirect effect $\times$ direct effect $(0.162$ $\times 0.781=0.126)$ was positive, these results indicated the existence of statistical evidence for a complementary mediation (Zhao et al., 2010). In particular, it could be concluded that there was a mediating effect of cooperative communication on the relationship between supervisor-nurse relationship and team effectiveness; therefore, $\mathrm{H} 3$ was supported.

Table 1: Regression summary for direct relationship

\begin{tabular}{|l|l|l|l|l|}
\hline & \multicolumn{2}{|l|}{ Cooperative communication } & \multicolumn{2}{l|}{ Team effectiveness } \\
\hline Predictors 1: Control & Model 1 & Model 2 & Model 3 & Model 4 \\
\hline $\begin{array}{l}\text { Step } \\
\text { variable }\end{array}$ & & & & \\
\hline Team size & $-0.202^{* *}$ & $-0.172^{* *}$ & $0.104^{*}$ & 0.010 \\
\hline Team tenure & $0.236^{* *}$ & $-0.208^{* *}$ & $-0.186^{*}$ & -0.085 \\
\hline $\begin{array}{l}\text { Step 2: Predictor } \\
\text { variable }\end{array}$ & & & & \\
\hline $\begin{array}{l}\text { Supervisor-nurse } \\
\text { relationship }\end{array}$ & & $0.148^{* *}$ & & $0.237^{* *}$ \\
\hline $\begin{array}{l}\text { Cooperative } \\
\text { communication }\end{array}$ & & & & $0.441^{* *}$ \\
\hline $\mathrm{R}^{2}$ & 0.104 & 0.202 & 0.039 & 0.088 \\
\hline Adjusted $\mathrm{R}^{2}$ & 0.096 & 0.191 & 0.026 & 0.071 \\
\hline$r^{2}$-change & 0.104 & 0.098 & 0.023 & 0.049 \\
\hline F-change & $4.935^{* *}$ & $4.905^{* *}$ & $8.367^{*}$ & $16.232^{* *}$ \\
\hline
\end{tabular}

Note: ${ }^{*} p<0.05{ }^{* *} p<0.01$ 
Table 2: Regression summary for mediation

\begin{tabular}{|c|c|c|c|c|c|}
\hline \multirow[t]{2}{*}{ Variables } & \multicolumn{4}{|c|}{ Direct, indirect and total effects } & \multirow{2}{*}{$\begin{array}{l}\text { Bootstrap for } \\
\text { indirect effect }\end{array}$} \\
\hline & 8 & $S E$ & $t$ & $P$ & \\
\hline $\begin{array}{l}\text { Team effectiveness } \\
\text { regressed on supervisor- } \\
\text { nurse relationship (path } \\
\text { c) }\end{array}$ & 0.618 & 0.060 & 10.210 & 0.000 & Effect $=0.162$ \\
\hline $\begin{array}{l}\text { Cooperative } \\
\text { communication } \\
\text { regressed on supervisor- } \\
\text { nurse relationship (path } \\
\text { a) }\end{array}$ & 0.366 & 0.077 & 4.706 & 0.000 & $\begin{array}{l}\text { Boot SE }= \\
0.031\end{array}$ \\
\hline $\begin{array}{l}\text { Team effectiveness } \\
\text { regressed on cooperative } \\
\text { communication, } \\
\text { controlling for supervisor- } \\
\text { nurse relationship (path } \\
\text { b) }\end{array}$ & 0.443 & 0.047 & 9.327 & 0.000 & $\begin{array}{l}\text { LL95\% } \\
0.105\end{array}$ \\
\hline $\begin{array}{l}\text { Team effectiveness } \\
\text { regressed on supervisor- } \\
\text { nurse relationship, } \\
\text { controlling } \\
\text { cooperative } \\
\text { communication (path c') }\end{array}$ & 0.781 & 0.052 & 14.770 & 0.000 & $\begin{array}{l}\text { UL95\% } \\
0.229\end{array}$ \\
\hline
\end{tabular}

Notes: Control variables include team size and team tenure; Boot SE= bootstrapped standard error; $L L=$ lower limit; $U I=$ upper limit; $C l=$ confidence interval. Bootstrapped sample size = 5000

\section{Discussion}

The findings of this study support $\mathrm{H} 1$ which predicts a significant influence between supervisor-nurse relationship and cooperative communication, and $\mathrm{H} 2$ which shows supervisor-nurse relationship and cooperative communication have a significant influence on team effectiveness in nursing teams in Malaysia. This relationship has been supported by previous studies, but the samples used were associated with certain areas of healthcare, such as neonatal intensive care and cardiology (Forouzi et al., 2016; Malmstrom et al., 2017). This research has expanded this evidence by providing a wider sample size of nurses working in different areas of medical specialisation units and hospitals.

The results also reveal cooperative communication's mediating effect on the relationship between supervisor-nurse relationship and team effectiveness, which supports H3. The study's findings clearly support previous arguments that cooperative communication is the main force that binds all organisational activities (Gharaveis et al., 2018; Mitchell et al., 2015). The theoretical model has proven useful to the nursing team which demonstrates that when team members have good communication such as information exchange and sharing opinions and also have a good leader. This consequently enhances the effectiveness of team outcome, and thus will increase patient safety and satisfaction. 
The number of practical implications extracted from the results was the basis for recommendations to the Ministry of Health $(\mathrm{MOH})$ and hospital management in empowering the effectiveness of nursing teams by identifying all possible factors that are involved. The study identified that poor quality of communication and lack of teamwork skills are detrimental to effective team performance in health care. Therefore, there is a need for a measured approach that incorporates teamwork competencies and proper communication channels such as formal training. This requires hospital-wide quality management systems at an organisational level. An excellent nursing teamwork performance would generate a good quality of patient treatment.

Furthermore, good leadership supports team performance and high-quality patient care. The outcomes of the research will serve as a guidance for the Ministry of Health on how to formulate and design policies in order to foster higher support for healthcare employees especially staff nurses and develop a robust linkage between them. Besides, leaders or hospital management should demonstrate a concern for employees' needs and feelings, providing help and information which are given clearly, and giving fruitful feedback. The leadership support at appropriate levels will ensure that employees can be better engaged in their jobs.

\section{Conclusion}

This study aims to discuss the connection between nurse-supervisor relationship and cooperative communication with team effectiveness. This study has verified that a positive relation was shown to exist between supervisor-nurse relationship and cooperative communication with team effectiveness. Furthermore, the result of this study also supports cooperative communication mediates supervisor-nurse relationship and team effectiveness. Thus, this study prove that the healthcare industry has a crucial need for teamwork which is globally acknowledged as a vital element in the provision of high-quality patient care.

\section{Limitations and Recommendations}

Related to other studies, this study also has some limitations. this study is limited to nurses who are working in public sector. The same research could be expanded among other health care employees from public and private hospitals. A larger sample in the same industry would improve the generalization of the findings. Future research also can consider and comparing on team effectiveness between public and private hospital health care teams.

Next, this study is cross-sectional nature. It is suggesting that a longitudinal design would improve ability to predict what factors influence team effectiveness. In longitudinal studies, the data will collect over time, because individuals' behavior are expected to change time to time. This longitudinal design will provide ample avenues to keep track of individuals' behavior especially in teamwork values and affect different relationship between immediate supervisor and subordinate.

Furthermore, this study suggests that future research examine the role of the other variables such as by looking at the organisational context of organisational culture, organisational systems, and management processes that impact team effectiveness. A further study could improve the understanding in the healthcare setting by using other techniques such as semistructed interviews as well as qualitative methods and behavioural observation. 


\section{Acknowledgements}

The authors thank all who participated in this study.

\section{Corresponding Author}

Muhammad Aiman Arifin

Faculty of Business and Management, Universiti Teknologi Mara Cawangan Perlis, Kampus Arau, 02600 Arau, Perlis, Malaysia.

Email: aimanarifin@uitm.edu.my

\section{References}

Adams, A. M. N., Chamberlain, D., \& Giles, T. M. (2019). The perceived and experienced role of the nurse unit manager in supporting the wellbeing of intensive care unit nurses: an integrative literature review. Australian Critical Care, 32(4), 319-329.

Afsar, B., \& Masood, M. (2018). Transformational leadership, creative self-efficacy, trust in supervisor, uncertainty avoidance, and innovative work behavior of nurses. The Journal of Applied Behavioral Science, 54(1), 36-61.

Ahmad, R., \& Saad, M. (2020). The Impact of Malaysian Public Sector in the Relationship between Transformational Leadership Styles and Career Development. International Journal of Public Administration, 43(3), 203-212.

Anderson, B. A. (2019). Facing the Nursing Workforce Shortage: Policies and Initiatives to Promote a Resilient Healthcare System. Caring for the Vulnerable: Perspectives in Nursing Theory, Practice, and Research, 363.

Azizan, F. L., Darus, A., \& Othman, N. (2017). Team coordination influencing team effectiveness: A study of nursing team. International Journal of Management Research and Reviews, 7(9), 893-901.

Azizan, F.L., Othman, N., Darus, A. (2017). Leader-Member exchange differentiation and team effectiveness among Malaysian nurses: Team potency as mediator. International Journal of Economic Research, 14(14PartII), 135-148.

Balkundi, P., \& Harrison, D. A. (2006). Ties, leaders, and time in teams: Strong inference about the effects of network structure on team viability and performance. Academy of Management Journal, 49, 49-68.

Bliese, P. D. (2000). Within-group agreement, non-independence, and reliability: Implications for data aggregation and analysis.

Borrott, N., Kinney, S., Newall, F., Williams, A., Cranswick, N., Wong, I., \& Manias, E. (2017). Medication communication between nurses and doctors for paediatric acute care: An ethnographic study. Journal of Clinical Nursing, 26(13-14), 1978-1992.

Brunetto, Y., Farr-Wharton, R., \& Shacklock, K. (2011). Supervisor-nurse relationships, teamwork, role ambiguity and well-being: Public versus private sector nurses. Asia Pacific Journal of Human Resources, 49(2), 143-164.

Brunetto, Y., Xerri, M., Farr-Wharton, B., Shacklock, K., Farr-Wharton, R., \& Trinchero, E. (2016). Nurse safety outcomes: old problem, new solution-the differentiating roles of nurses' psychological capital and managerial support. Journal of Advanced Nursing, 72(11), 2794-2805.

Busari, J. O., Moll, F. M., \& Duits, A. J. (2017). Understanding the impact of interprofessional collaboration on the quality of care: a case report from a small-scale resource limited health care environment. Journal of multidisciplinary healthcare, 10, 227. 
Chen, G., Tjosvold, D., \& Liu, C. (2006). Cooperative goals, leader people and productivity values: Their contribution to top management teams in China. Journal of Management Studies, 43(5), 1177-1200.

Chiniara, M., \& Bentein, K. (2018). The servant leadership advantage: When perceiving low differentiation in leader-member relationship quality influences team cohesion, team task performance and service OCB. The Leadership Quarterly, 29(2), 333-345.

Cogliser, C. C., \& Schriesheim, C. A. (2000). Exploring work unit context and leader-member exchange: A multi-level perspective. Journal of organizational Behavior, 21(5), 487-511.

Ferlie, E. B., \& Shortell, S. M. (2001). Improving the quality of health care in the United Kingdom and the United States: a framework for change. The Milbank Quarterly, 79(2), 281-315.

Forouzi, A. M., Heidarzadeh, A., Kazemi, M., Jahani, Y., \& Afeshari, M. (2016). Comparison of the combined based with the mannequin based simulation models in self efficacy, performance and satisfaction of nursing students on cardiopulmonary resuscitation. Asian Journal of Nursing Education and Research, 6(1), 69.

Gharaveis, A., Hamilton, D. K., Pati, D., \& Shepley, M. (2018). The impact of visibility on teamwork, collaborative communication, and security in emergency departments: An exploratory study. HERD: Health Environments Research \& Design Journal, 11(4), 37-49.

Graen, G. B., \& Uhl-Bien, M. (1995). Relationship-based approach to leadership: Development of leader-member exchange (LMX) theory of leadership over 25 years: Applying a multilevel multi-domain perspective. Leadership Quarterly, 6, 219-247.

Grover, E., Porter, J. E., \& Morphet, J. (2017). An exploration of emergency nurses' perceptions, attitudes and experience of teamwork in the emergency department. Australasian Emergency Nursing Journal, 20(2), 92-97.

Hackman, J. R. (1990). Groups that work and those that don't (No. E10 H123). Jossey-Bass.

Halim, H., \& Azizan, F. L. (2017). Examining Malaysian leader characteristics in a managerSubordinate relationship. Jurnal Komunikasi: Malaysian Journal of Communication, 33(3).

Havold, J. I., \& Havold, O. K. (2019). Power, trust and motivation in hospitals. Leadership in Health Services, 32(2), 195-211.

Hayes, A. F. (2013). Introduction to mediation, moderation, and conditional process analysis: A regression-based approach. Guilford Press.

Huang, I. C., Du, P. L., Wu, L. F., Achyldurdyyeva, J., Wu, L. C., \& Lin, C. S. (2021). Leadermember exchange, employee turnover intention and presenteeism: the mediating role of perceived organizational support. Leadership \& Organization Development Journal.

Hughes, A. M., Gregory, M. E., Joseph, D. L., Sonesh, S. C., Marlow, S. L., Lacerenza, C. N., ... Salas, E. (2016). Saving lives: A meta-analysis of team training in healthcare. Journal of Applied Psychology, 101, 1266-1304.

James, A. H., Bennett, C. L., Blanchard, D., \& Stanley, D. (2021). Nursing and values-based leadership: A literature review. Journal of Nursing Management.

James, L. R., Demaree, R. G., \& Wolf, G. (1993). Rwg: An assessment of within-group interrater agreement. Journal of applied psychology, 78(2), 306.

Jha, S. (2017). Mediation of superior-subordinate relationship and a climate of innovation on psychological empowerment. International Journal of Productivity and Performance Management, 66(7), 932-947.

Kaiser, J. A., \& Westers, J. B. (2018). Nursing teamwork in a health system: A multisite study. Journal of Nursing Management, 26(5), 555-562. 
Kalisch, B. J., \& Lee, K. H. (2010). The impact of teamwork on missed nursing care. Nursing Outlook, 58(5), 233-241.

Kalisch, B. J., Lee, H., \& Rochman, M. (2010). Nursing staff teamwork and job satisfaction. Journal of nursing management, 18(8), 938-947.

Katzenbach, J. R., \& Smith, D. K. (1993). The rules for managing cross-functional reengineering teams. Planning Review.

Keogh, T. J., Robinson, J. C., \& Parnell, J. M. (2019). Assessing behavioral styles among nurse managers: Implications for leading effective teams. Hospital topics, 97(1), 32-38.

Keyton, J. (2014). Communication, organizational culture, and organizational climate. The Oxford handbook of organizational climate and culture, 118-135.

Lee, J. (1997). Leader-member exchange, the "Pelz effects" and cooperative communication between group members. Management Communication Quarterly, 11, 266-287.

Liden, R.C., Erdogan, B., Wayne, S. J., \& Sparrowe, R.T. (2006) Leader-member exchange, differentiation, and task interdependence: implications for individual and group performance. Journal of Organizational Behavior, 27(6), 723-746.

Liden, R.C., \& Maslyn, J.M. (1998). Multidimensionality of leader-member exchange: An empirical assessment through scale development. Journal of Management, 24(1), 4372.

Malmstrom, B., Nohlert, E., Ewald, U., \& Widarsson, M. (2017). Simulation-based team training improved the self-assessed ability of physicians, nurses and midwives to perform neonatal resuscitation. Acta Paediatrica, 106(8), 1273-1279.

Mitchell, R., Boyle, B., Parker, V., Giles, M., Chiang, V., \& Joyce, P. (2015). Managing inclusiveness and diversity in teams: How leader inclusiveness affects performance through status and team identity. Human Resource Management, 54(2), 217-239.

Morsiani, G., Bagnasco, A., \& Sasso, L. (2017). How staff nurses perceive the impact of nurse managers' leadership style in terms of job satisfaction: a mixed method study. Journal of Nursing Management, 25(2), 119-128.

Mueller, B. H., \& Lee, J. (2002). Leader-member exchange and organizational communication satisfaction in multiple contexts. The Journal of Business Communication (1973), 39(2), 220-244.

Nelsey, L., \& Brownie, S. (2012). Effective leadership, teamwork and mentoring-Essential elements in promoting generational cohesion in the nursing workforce and retaining nurses. Collegian, 19(4), 197-202.

Neter, J., Wasserman, W., \& Kutner, M. H. (1985). Applied linear statistical models: regression, analysis of variance, and experimental designs. RD Irwin: Homewood, IL.

Ong, L., Sani, M., \& Soh, K. G. (2018). Nursing Workload in Relation to Nosocomial Infection in Public Hospital Intensive Care Unit, Malaysia. International Journal of Pharmaceutical Research, 10(4).

Othman, N., \& Nasurdin, A. M. (2019). Job characteristics and staying engaged in work of nurses: Empirical evidence from Malaysia. International journal of nursing sciences, 6(4), 432-438.

Polis, S., Higgs, M., Manning, V., Netto, G., \& Fernandez, R. (2017). Factors contributing to nursing teamwork in an acute care tertiary hospital. Collegian, 24(1), 19-25.

Preacher, K. J., Rucker, D. D., \& Hayes, A. F. (2007). Addressing moderated mediation hypotheses: Theory, methods, and prescriptions. Multivariate Behavioral Research, 42(1), 185-227. 
Rodwell, J., McWilliams, J., \& Gulyas, A. (2017). The impact of characteristics of nurses' relationships with their supervisor, engagement and trust, on performance behaviours and intent to quit. Journal of advanced nursing, 73(1), 190-200.

Sin, H.P., Nahrgang, J D., \& Morgeson, F.P. (2009). Understanding why they don't see eye to eye: An examination of leader-member exchange (LMX) agreement. Journal of Applied Psychology, 94(4), 1048.

Sonoda, Y., Onozuka, D., \& Hagihara, A. (2018). Factors related to teamwork performance and stress of operating room nurses. Journal of Nursing Management, 26(1), 66-73.

Spector, P. E., \& Brannick, M. T. (2011). Methodological urban legends: The misuse of statistical control variables. Organizational Research Methods, 14(2), 287-305.

Srulovici, E., \& Drach-Zahavy, A. (2017). Nurses' personal and ward accountability and missed nursing care: A cross-sectional study. International journal of nursing studies, $75,163-$ 171.

Sui, Y., Wang, H., Kirkman, B. L., \& Li, N. (2016). Understanding the curvilinear relationships between LMX differentiation and team coordination and performance. Personnel Psychology, 69(3), 559-597.

Ulrich, B. (2017). Using Teams to Improve and Performance. Nephrology Nursing Journal, 44(2).

Wang, Y., Wan, Q., Guo, J., Jin, X., Zhou, W., Feng, X., \& Shang, S. (2018). The influence of effective communication, perceived respect and willingness to collaborate on nurses' perceptions of nurse-physician collaboration in China. Applied Nursing Research, 41, 73-79.

Wassem, M., Baig, S. A., Abrar, M., Hashim, M., Zia-Ur-Rehman, M., Awan, U., ... \& Nawab, Y. (2019). Impact of capacity building and managerial support on employees' performance: The moderating role of employees' retention. SAGE Open, 9(3), 2158244019859957.

Welp, A., Meier, L. L., \& Manser, T. (2016). The interplay between teamwork, clinicians' emotional exhaustion, and clinician-rated patient safety: a longitudinal study. Critical Care, 20(1), 110.

Zhao, X., Lynch Jr, J. G., \& Chen, Q. (2010). Reconsidering Baron and Kenny: Myths and truths about mediation analysis. Journal of Consumer Research, 37(2), 197-206. 